\section{Short-term alpha- or gamma-delta-enriched tocopherol oil supplementation differentially affects the expression of proinflammatory mediators: selective impacts on characteristics of protein tyrosine nitration in vivo}

\author{
Ted H. Elsasser, 1 Stanislaw Kahl,1 \\ Katie M. Lebold,2 Maret G. Traber,2 \\ Jessica Shaffer,1 Cong-Jun Li,1 \\ Stephanie Block ${ }^{3}$
}

1 Agricultural Research Service, Bovine Functional Genomics Laboratory, U. S. Department of Agriculture, Beltsville, MD; 2Linus Pauling Institute, Oregon State University, Corvallis, OR, ${ }^{3}$ Archer Daniels Midland, Inc., Decatur, IL, USA

\section{Abstract}

While vitamin $\mathrm{E}$ has been used for decades in cattle diets, the principle form used traditionally is the synthetic $\alpha$-isoform acetate or succinate and largely no data exist on the biological partitioning or functionality of the major naturally occurring $\gamma$ - and $\delta$-isoforms in cattle. Using tyrosine 3'-nitrated protein (pNT) as a biomarker of nitrosative cell stress, we sought to evaluate the effectiveness of shortterm feeding supplementation of high content natural $\alpha$-tocopherol ( $\alpha$-T, 96\% $\alpha$-isomer) compared to high content $\gamma$ - and $\delta$-enriched low $\alpha$-content mixed tocopherol oils $(\gamma-T, \sim 70$ $\% \gamma-, 20 \% \delta$-, $<5 \% \alpha$-isoform) to mitigate systemic and hepatic aspects of the proinflammatory response to endotoxin (LPS). Calves fed diets supplemented with $\alpha-T, \gamma-T$ for five days or no tocopherol supplement (TOE) were challenged with a low-level of LPS $(0.25 \mathrm{~g} / \mathrm{kg}$, iv, $E$. coli 055 :B5) sufficient to effect a liver nitration response. As fed, $\alpha-T$ or $\gamma-T$ increased plasma and liver content of the respective tocopherols reflecting their relative abundance in the respective diets. Plasma or tissue mediators and biomarkers of the proinflammatory response [plasma concentrations of tumor necrosis factor- $\alpha \quad($ TNF- $\alpha, \quad P<0.001)$, nitrate+nitrite $(\mathrm{NOx},, \mathrm{P}<0.01)$, and serum amyloid A (SAA, $\mathrm{P}<0.001)$ ], and general liver content of pNT $(\mathrm{P}<0.005)$ increased after LPS. LPS-mediated increases in TNF- $\alpha$ were not different between diet treatments; both plasma NOx $(\mathrm{P}<0.05)$ and generalized liver pNT $(\mathrm{P}<0.03)$ responses were attenuated significantly in $\alpha-T$ and $\gamma$-T versus TOE calves. Plasma SAA was significantly decreased in $\gamma-T$ calves at $24 \mathrm{~h}$ post-LPS relative to responses in $\alpha$-T or
TOE calves. The nitration of the mitochondrial proteins $24 \mathrm{~h}$ post-LPS was not only attenuated in $\alpha-T$ and $\gamma-T$ vs TOE, but also the mitigating effect of $\gamma-T$ on these specific nitration events was greater than that of $\alpha-T(\mathrm{P}<0.01)$. Results are consistent with the concept that short-term $\alpha-T$ or $\gamma-T$ supplementation can effectively decrease proinflammatory liver pNT after LPS; some mitochondrial nitration targets may be better protected with prophylactic supplementation with $\gamma-, \delta$-tocopherol enriched oil.

\section{Introduction}

The liver plays an unquestionably critical role in maintaining metabolic and homeostatic balance during states of good health and in restoring this balance during bouts of disease. Contributing to both hepatic and a systemic progression of disease, subtoxic stresses in the liver [ such as those associated with situational induction of TNF- $\alpha$, arachidonic acid mediators, superoxide anion, $\left(\mathrm{O}_{2} \bullet\right)$, or $\mathrm{H}_{2} \mathrm{O}_{2}$ production] can slant the hepatic cellular response to stress towards aberrant function with progressive consequences unless converging pathways are interrupted.1,2 Across the spectrum of possible hepatocellular responses to proinflammatory stress, two areas of perturbed function are energy/ATP production and energy partitioning as reflected, for example, in the ATP-to-AMP ratio, and AMP-kinase activity 3,4 and signal transduction efficiency in hormone-driven metabolic pathways. ${ }^{5,6}$ However, energy production and mitochondrial function are intrinsically linked to nutrient availability and the hierarchy of partitioning among and between tissues as dictated by health status and effected through alterations in hormone and cytokine signaling.7-10 As such, small perturbations in the integrity of mitochondrial lipid membranes and associated protein function (i.e., proton pumps, electron transport chain Complexes I-IV, Complex V, etc.) result in decreased efficiency of electron shuttling down the electron transport chain and impaired ATP formation in association with compromised Complex-V: F1F0-ATP-synthase activity. ${ }^{10-13}$ When this occurs, concomitant increases in $\mathrm{O}_{2} \bullet$ and nitric oxide (NO) generation frequently are observed,11,13 along with increased likelihood of peroxynitrite (ONOO-) formation and the generation of tyrosine nitrated proteins, 14 with evidence of this occurring in the mitochondria independent of arginine-dependent pathways. 15

Close associations exist between proinflammatory mediators of the innate immune response (NO and $0^{2} \bullet$ and reactive oxynitrogen compounds derived from them like $\mathrm{ONOO}^{-}$), the nitration of select tyrosine residues of proteins, and cellular pathology in several
Correspondence: Ted H. Elsasser, U. S. Department of Agriculture, Bovine Functional Genomics Laboratory, Bldg 200, R 201, B.A.R.C. East, Beltsville, MD 20705, USA.

Tel. +1.301.504.8281.

E-mail: theodore.elsasser@ars.usda.gov

Key words: endotoxin, liver, mitochondria, protein nitration, vitamin $\mathrm{E}$

Contributions: THE, Principle Investigator, concept of experiment, study design and conduct, sample collection, light microscopy, quantitative immunohistochemistry, statistical analysis, manuscript preparation; SK, sample preparation, liver biology, statistical analysis, final manuscript approval; KML, sample preparation, vitamin E analysis; MGT, vitamin E analysis, final manuscript approval; C-JL, biochemical analysis; JLS, technical assistance, sample collection; SB, resource consultant, study design, final manuscript approval.

Conflict of interests: collectively no authors had conflicts of interest. SB is employed by Archer Daniels Midland, Inc. and facilitated the donation of the tocopherol oil preparations as used in the study. Mention of a product, reagent or source does not constitute an endorsement by the USDA to the exclusion of other products or services that perform a comparable function.

Funding: this research was conducted in toto through base funding allotted to the USDA, Bovine Functional Genomics Laboratory.

Received for publication: 30 January 2013. Accepted for publication: 6 February 2013

This work is licensed under a Creative Commons Attribution NonCommercial 3.0 License (CC BYNC 3.0).

CC Copyright T.H. Elsasser et al., 2013 Licensee PAGEPress srl, Italy

Veterinary Science Development 2013; 3:e6 doi:10.4081/vsd.2013.e6

organs. ${ }^{16-18}$ Tyrosine nitration has been linked to altered protein function (mostly decreased but occasionally increased activity) ${ }^{19}$ and specific manifestations of disease ${ }^{17,18}$ including LPS-mediated proinflammatory syndrome ${ }^{6,20}$ and distinct perturbations in mitochondria. ${ }^{14,15}$ Our laboratory described previously several perturbations in liver function that were strongly associated with a proinflammatory induction of generalized as well as specific signal transduction-related protein tyrosine nitration responses in calf liver.6,19,21 In light of our results and the biological impact of $0 \mathrm{NOO}$ reported by others, we considered the potential to modulate the reactivity of $\mathrm{ONOO}^{-}$an achievable goal in the attempt to mitigate some of the possible negative attributes of nitrooxidative 
stress arising from both mitochondrial and cytosolic perturbations. Key to resolving this is targeting for remediation those impact points that have the greatest benefit with the least collateral impact on the nitric oxide and superoxide anion generating pathways. Herein we describe the capacity for short-term feeding of dietary formulations of tocopherols differing in isoform content to affect the generation of nitrated proteins in the liver as effected by administering LPS in a large animal (calf) model of proinflammatory response known to promote nitrotyrosine formation. 6,20

\section{Materials and Methods}

\section{Vitamin $\mathrm{E}$ formulations}

Vitamin E preparations were natural products derived and concentrated from soy bean oil, analyzed by and kindly provided by Archer Daniel Midland (ADM, Decatur, IL, USA). The Vitamin $E$ product used as a high content $\alpha$ tocopherol isoform was Novatol 1490 $0^{\mathrm{TM}}$ Vitamin E oil containing $R R R$ - $\alpha$-tocopherol $(960 \mathrm{mg} / \mathrm{g})$. The vitamin E product used as a high-content $\gamma$ $\delta$-tocopherol oil with low $\alpha$-tocopherol level was Decanox MTS-90G ${ }^{\text {TM }}$ Mixed Tocopherols containing $\gamma$-tocopherol $(600 \mathrm{mg} / \mathrm{g}), \delta$-tocopherol (175 mg/g), $\beta$-tocopherol $(\sim 20 \mathrm{mg} / \mathrm{g})$ and $\alpha$ tocopherol ( $68 \mathrm{mg} / \mathrm{g})$.

\section{Animals and proinflammatory chal- lenge protocols}

All protocols and procedures involving animals were preapproved by the USDA Beltsville Area Animal Care and Use Committee (Protocol \#ACUC 08-008). Angus x Hereford male calves were bred and born at the USDA Beltsville Beef Cattle Research Unit. At the time of study, calves ( $\mathrm{n}=21$; mean body weight: $211 \pm 6 \mathrm{~kg}$ ) were group penned and group fed in equal numbers across three test diet assignments. The base diet was a total mixed cattle ration formulated from aged corn and grass silages with added cracked corn, soy bean meal and dicalcium phosphate, molasses, vitamin A, vitamin $\mathrm{D}$, and a commercial mineral mix. By analysis, the diet provided $49.8 \%$ dry matter (DM) and $13.4 \%$ available crude protein $/ \mathrm{kg} \mathrm{DM}$ with a calculated metabolizable energy (ME) of $1.96 \mathrm{Mcal} / \mathrm{kg}$ DM.22 Daily the group feed bunk was cleaned and replenished with $170 \mathrm{~kg}$ (as fed) base diet. Dietary treatments were designated as control (TOE, base diet with corn meal carrier), $\alpha$-tocopherol supplemented ( $\alpha-T$, base diet with Novatol $\left.{ }^{\mathrm{TM}} 1490\right)$, or $\gamma-$, $\delta$ enriched tocopherol supplemented $(\gamma-T$, base diet with Decanox ${ }^{\mathrm{TM}}$ MTS-90 G). In this feeding supplementation trial, the calculated total average daily tocopherol intake/calf (assumed equal intake) of Novatol ${ }^{\mathrm{TM}}$ was $1250 \mathrm{mg} / \mathrm{calf}$ and for Decanox ${ }^{\mathrm{TM}} 3850 \mathrm{mg} / \mathrm{calf}$. To provide this, the required total amount of each tocopherol oil was added to a set amount of carrier (5 kg corn meal) and mixed 10 minutes to homogeneity in a vertical mixer (Hobart Corporation, Troy, OH, USA). Carrier corn meal and tocopherol-supplemented corn meal mixes were applied uniformly on top of the total measured day's fresh feed and fed daily for five days. The proportionately larger amount of Decanox ${ }^{\mathrm{TM}}$ fed was estimated to compensate in part for the assumed faster turnover of $\gamma$ and $\delta$-tocopherols (compared to $\alpha$-tocopherol) ${ }^{23-25}$ where no comparative data exist in the literature on the liver content, turnover or plasma concentrations and half-life of these tocopherol formulations as fed to bovine species. Control calves received only an equivalent amount of the corn meal carrier as added to the feed bunk daily.

In order to minimize potential sources of variability documented to occur in response to LPS challenge, ${ }^{6}$ animals for the trials were chosen from the herd based on age, level of feed intake, uniformity of growth, health, and temperament. One month prior to use in the LPS challenge protocol, each animal was treated with a broad spectrum antibiotic (florfenicol, Nuflor ${ }^{\mathrm{TM}}$, Schering-Plough Animal Health, Summit, NJ, USA), vaccinated for respiratory and gastrointestinal viruses and given treatment for endo- and exoparasites (Ivomec ${ }^{\circledR}$, Merial Corp., Duluth, Ga). After 4 d of supplement feeding and in preparation for the immune challenge, an indwelling 14 ga. Teflon ${ }^{\circledR}$ cannula (Abbocath, Abbot Lab., No. Chicago, IL, USA; $0.5 \mathrm{~mL}$ void volume) was introduced into the jugular vein of each calf with aseptic technique. The patency of the cannula was maintained by periodically flushing with $0.4 \mathrm{~mL}$ sterile saline containing 20 units/mL lithium heparin. Following the fifth morning of diet treatment feeding, calves were challenged one time with LPS $(0.25 \mathrm{~g} / \mathrm{kg} \mathrm{BW}$; E. coli 055:B5, Sigma, St. Louis, M0, USA; i.v. bolus via jugular catheters) as previously described in our laboratory20,21 and jugular blood samples (EDTA or lithium heparin anticoagulant for plasma) collected at -24, 0, 1.5, 7, and $24 \mathrm{~h}$ relative to LPS injection. Liver samples were obtained by intercostal transcutaneous biopsy ( 3 samples, $25 \mathrm{mg}$ each as specified by animal care protocol) using a $1 \mathrm{~mm}$ diameter surgical trochar (Pharmaseal Truecut; Allegiance Healthcare Corp., McGraw Pk., IL, USA) at $24 \mathrm{~h}$ before ( $-24 \mathrm{~h})$ and $24 \mathrm{~h}$ after $(+24$ h) LPS injection as previously described.20,21 Plasma samples were stored at $-25^{\circ} \mathrm{C}$ pending analysis; liver samples were either snap frozen in liquid nitrogen and stored at $-85^{\circ} \mathrm{C}$ or fixed in $4 \%$ paraformaldehyde, transferred to $70 \%$ ethanol for subsequent paraffin-embedding and sectioning for immunohistochemistry.

\section{Plasma and tissue tocopherol con-} tent and stress biomarkers

In order to assure that feeding the different tocopherol oil matrices effectively changed plasma and liver content of tocopherols, $\alpha$ - and $\gamma$-tocopherol was extracted from plasma and liver and analyzed by HPLC as previously described and validated. ${ }^{26}$ Plasma concentrations of TNF- $\alpha$ (radioimmunoassay), nitrite + nitrate (enzyme assay, NOx, expression of nitric oxide response), acute phase response protein (ELISA; serum amyloid A, SAA) were measured in our laboratory as previously described. ${ }^{27-29}$

\section{Immunohistochemistry}

We assessed and quantified the impact of LPS-mediated proinflammatory stress on the liver in terms of the cellular content (pixel density) of total generalized nitrated protein as well as the specific nitration of mitochondrial proteins in biopsy specimens ( -24 and +24 $h$ relative to the administration of LPS challenge) by quantitative immunohistochemistry. The protocols for this were previously validated in our laboratory. ${ }^{20,21}$ In order to increase the uniformity of the respective immunostaining procedures, each paraffin block contained biopsy samples representing one full replicate of dietary and LPS treatment and, in addition, each slide contained one piece of one biopsy core as a positive control from an animal known to have mounted, in a previous study, an intense nitration response to LPS challenge. ${ }^{21}$ Each slide-mounted tissue section was deparaffinized with toluene, transferred to ethyl alcohol washes, treated with $0.3 \% \mathrm{H}_{2} \mathrm{O}_{2}$ in methanol to mitigate pseudoperoxidase activity, and hydrated through decreasing concentration of ethanol to water. Antigen retrieval was accomplished with a standard hot citrate protocol with further permeabilizing treatment for 10 minutes with $0.1 \%$ Triton X100 . Nonspecific binding was blocked by preincubation in $3 \%$ normal serum for the secondary antibody species in TRIS-saline containing $0.1 \%$ casein. Nitrated proteins were identified using rabbit anti-nitrotyrosine serum (1:5000; kindly provided by Dr. J. Rodrigo, Institudo de Cajal, Madrid, Spain) with visualization of the antigen signal accomplished with a commercial horseradish peroxidase and diaminobenzidine (DAB) kit (Vecta-Stain Elite $®$, Vector Laboratories, Burlingame, Ca). In order to increase uniformity across specimen slides, immunostaining protocols were conducted in dip tanks wherever possible (all preparative steps through blocking and antigen retrieval, all washing, and reaction with diaminobenzidine, DAB) and in other instances reagents were prepared in bulk and rapidly applied to individual slides when steps required a flat horizontal reagent application in a humidified 
incubation chamber. After resolution of nitrotyrosine antigen signal, nuclei were counterstained with Carrazzi's hematoxylin (1 minute), washed with tap water, dehydrated through absolute ethanol to toluene and cover slips added.

\section{Proximity ligation assay for mito- chondria-specific nitration}

The specific nitration of mitochondrial proteins was evaluated and quantified using a proximity ligation assay protocol (Duolink ${ }^{\circledR}$ PLA, Olink Biosciences, Uppsala, Sweden). In this assay, two different antigens (in this case a mitochondrial protein epitope and the nitrotyrosine epitope) present at a distance of $40 \mathrm{~nm}$ or less permit the colocalized generation of an event signal that can be quantified by image analysis with regard to number of events, size of the complex events and intensity of events. ${ }^{30}$ Using the same tissue specimens described above, nitrated mitochondrial protein generation was detected using rabbit polyclonal antinitrotyrosine (1:7000) in conjunction with mouse monoclonal anti-bovine Complex V $\quad \alpha$-subunit $(0.75 \quad \mathrm{~g} / \mathrm{mL}$; Mitosciences Inc., Eugene, OR, USA). Even though the mitochondrial epitope antibody was directed to the Complex $\mathrm{V}$, any presence of nitrotyrosine within the $40 \mathrm{~nm}$ locale could constitute a mitochondrial nitration even if it was associated with a different mitochondrial protein as nitrations are known to occur in mitochondria. ${ }^{31}$ The amplification product generated by the rolling PCR was optimized (signal: noise) with a two hour incubation at $38^{\circ} \mathrm{C}$ in a humidity chamber. Following the amplification and linking procedures, the nucleotide-conjugated horseradish peroxidase reporter was hybridized to the rolling PCR product and reacted with Nova-Red ${ }^{\mathrm{TM}}$ to reveal the localization of the nitrated mitochondrial proteins. Nuclei were counterstained using Carrazzi's hematoxylin.

\section{Quantitative image analysis}

\section{General process}

For both general nitrotyrosine immunohistochemistry, quantification of signal events was accomplished using customized protocol applications similar to those described previously for Image-Pro® Image Analysis Software (Media Cybernetics, Rockville, MD).20,21 Eight digital images $(4080 \times 3072$ resolution) were captured (Olympus BX-40 microscope equipped with an Olympus DP-70 CCD camera) spanning the length of each biopsy core. The method used to quantify the extent of generalized protein tyrosine nitration was based on the processing algorithm (Image-Pro® software; color cube-based segmentation selection) representing the nitration response as a function of a conservative pixel identifica- tion rubric aimed at minimizing false positive signals by thresholding positive NT presence (reddish brown spectrum) through prefiltering with 8-connect and smoothing options enabled. ${ }^{21}$ Similarly, a spectrum representative of hematoxylin (blue) uptake into the nucleus was established and gated with size and morphological (close plus erode) filtering and watershed splitting of spatially close structures for cell counting and normalization of the nitration response data (pixels/cell) across the specimen fields of image capture.

\section{Quantifying and characterizing proximity ligation assay-detected nitration events}

Proximity ligation assay-detected proteinspecific nitration events were quantified in terms of the absolute number of Complex $\mathrm{V}$ alpha-subunit nitration events as well as the relationship between the intensity (pixel area) of the nitration events and the frequency at which the intensity of a particular size occurred. Nonspecific reactivities (lower limit pixel threshold acceptance) were controlled and eliminated from final statistical calculations by using negative control slides of liver biopsy tissue from healthy cattle as well as positive control tissue from LPS-challenged animals processed either without primary antibodies or the PLA rolling PCR reagents. From these slides any nonspecific spectral hues or pixel clusters below threshold generated from the detection substrate (Nova Red ${ }^{\mathrm{TM}}$ precipitation via horseradish peroxidase) were identified and deleted from the applied segmentation/quantification algorithm. For mathematically characterizing the relationship between the intensity of a nitration response and the frequency of that occurrence, the spectrum of acquired pixel areas for a given image were stratified into blocks of 50 pixels (50 to 99,100 to 149 , etc.) and the summed number of occurrences of an event within a given stratification used as the variable called frequency. Fifty pixels was set as the lowest area unit statistically associated with a valid subunit nitration response significantly above background and random noise as established on the image validation slides of tissues previously described. The resulting curvilinear plot of the pixel data (X-axis = frequency; Y-axis = intensity) for each animal was further analyzed by mathematical processing of the generated curve into two optimized linear segments analogous to the graphical analysis curve peeling process used to describe data from a two-compartment pool model. ${ }^{32,33}$ With this approach we created variable termed break point (BP) which corresponded to the point of intersection of the two regressed linear components of the curves. The derived BP reflects the point on the Y-axis (nitration event area) where high frequency and low intensity nitrations transition into the second component as high intensity (large area) and low frequency pixel areas.

\section{Statistical analysis}

Data were statistically analyzed by analysis of variance using mixed model regression (Proc Mixed; SAS). ${ }^{34}$ In the statistical model, diet supplement, LPS, and time were set as the main effects with an animal within diet as the error term; differences between individual dietary supplement treatments were further differentiated using specific contrast statements. In the final statistical analysis 4 animals of the starting 21 were eliminated from consideration. One TOE animal was eliminated because of failure to mount any plasma TNF- $\alpha$ response to the injected LPS. Two animals were eliminated from the $\alpha-T$ group; one animal died prior to the $24 \mathrm{~h}$ post LPS sampling because of apparent congenital pericardial tamponade defect discovered upon necropsy and another eliminated because of behavioral aggressiveness and hyper-reactivity to human handling. One animal was eliminated from the $\gamma-T$ group because of fever on the morning of sampling prior to LPS challenge, elevated clinical serological enzymes. This animal was subsequently diagnosed with a mild bacterial pneumonia.

\section{Results}

With ad libitum feeding for the one-month period immediately prior to the study, each calf averaged $1.28 \pm 0.2 \mathrm{~kg}$ live body weight gain/day with an estimated average daily consumption of $13.6 \mathrm{~kg}$ of dry matter diet. During the period when tocopherol supplementation was provided, daily feed allotment per animal was provided at a calculated $90 \%$ ad libitum intake to ensure complete ingestion of feed offered. The applied dietary supplementation treatments were effective in increasing the tissue and jugular plasma content of the respective predominant tocopherol isoforms. Plasma content and liver distribution patterns of the $\alpha$ - and $\gamma$ tocopherol isoforms are presented and summarized in Figures 1 and 2, respectively. Prior to tocopherol supplementation mean plasma concentrations of $\alpha$ - and $\gamma$-tocopherol were 4.78 and $0.18 \mathrm{nmol} / \mathrm{g}$ plasma, respectively, with no significant differences between experimental groups (Figure 1). For samples obtained on day 5 of feeding at time 0 relative to LPS challenge, mean plasma $\alpha$-tocopherol concentration increased $116 \%$ in $\alpha-T(\mathrm{P}<0.01 v$ TOE and $\gamma-T$ ) and $28 \%$ (NS v TOE) in $\gamma-T$. Plasma content of $\alpha$-tocopherol declined significantly by $24 \mathrm{~h}$ post LPS in $T O E$ and $\alpha-T(\mathrm{P}<0.05)$. The plasma content of $\gamma$-tocopherol was not affected by the increased intake of the $\alpha$-tocopherol in $\alpha$-T at any sample time. Feeding supplemental $\gamma$-tocopherol for 5 days resulted in a 
mean $\gamma$-tocopherol in plasma 12.5 fold (1100\%) higher than that of $T O E$ and $\alpha-T(\mathrm{P}<0.005)$. The plasma content of $\alpha$-tocopherol was not affected by the increased intake of the non$\alpha$-isoforms of tocopherols in $\gamma-T$. Mean concentrations of $\gamma$-tocopherol in plasma were not changed after LPS in either TOE or $\alpha$-T groups; mean concentrations of $\gamma$-tocopherol declined $(\mathrm{P}<0.05)$ on average $29 \%$ in $\gamma-T$ after LPS $(\mathrm{P}<0.05)$.

Feeding a diet enriched in high content $\alpha$ tocopherol resulted in a mean liver content triple that measured in calves fed the control diet and without any effect of the $\gamma$-tocopherol content of those livers (Figure 2). Conversely, the group fed the $\gamma$-enriched diets had a mean $\gamma$-tocopherol content 5.4 times that of non-supplemented animals. Interestingly, as can be seen in the top panel of Figure 2, consumption of a diet supplemented with the formulation of $\gamma$-tocopherol ( $5 \% \alpha$-tocopherol content as supplied Decanox MTS-90GTM preparation) resulted in a doubling of the $\alpha$-tocopherol content of these livers, an increase largely disproportionate to the amount fed. The reasons for this are largely speculative and beyond the present scope of this report. Liver levels of both $\alpha$ - and $\gamma$-tocopherol measured in samples collected $24 \mathrm{~h}$ after LPS were not different, respectively, from those measured prior to LPS.

Plasma concentration of TNF- $\alpha$, a principle biomarker for cytokine initiation of the proinflammatory cascade after LPS challenge, increased in all steers following LPS administration $(\mathrm{P}<0.001$, Figure 3). Plasma TNF- $\alpha$ were not affected by diet treatment at $0,1.5$ or $7 \mathrm{~h}$ post-LPS as reflected in either the absolute concentrations or the calculated area under the time $\mathrm{x}$ concentration response curves (AUC). There was a tendency for the peak (at $1.5 \mathrm{~h})$ TNF- $\alpha$ concentrations in $\gamma$-T steers to be lower than those measured in the steers of the other diet treatment groups, but the difference $(-12 \%)$ was not statistically significant $(\mathrm{P}<0.07)$.

The progression of the inflammatory response beyond the initiating proinflammatory cytokine response can be followed by measuring plasma concentration changes in NOx, the oxidation metabolites of NO, as a biomark- er for the activation of the NO cascade. These data furnished an interesting view of how animals responded to immune challenge not only as effected by LPS initiation of the proinflammatory cascade, but also as further influenced by the basic response of the animals to the handling, cannulation, and biopsy procedure performed one day prior to the application of the intended LPS challenge. As shown in Figure 4, plasma NOx concentrations were relatively low in baseline plasma samples obtained immediately prior to the preliminary liver pre-LPS biopsy sampling (-24 h). Plasma concentrations of $\mathrm{NOx}$ averaged $3.4 \mu \mathrm{mol} / \mathrm{L}$ across the diet treatment groups (NS diet effect). Plasma NOx concentrations increased 7-fold across diet treatment groups $24 \mathrm{~h}$ after preliminary liver biopsy. However, these increases were not accompanied by any clinical signs of illness as measured by rectal temperature or clinical serology. Interestingly, these measured increases in the baseline NOx concentrations at the start of LPS challenge were significantly higher in the TOE compared with either $\alpha-T$ or $\gamma-T$ animals $(\mathrm{P}<0.01)$ sug-

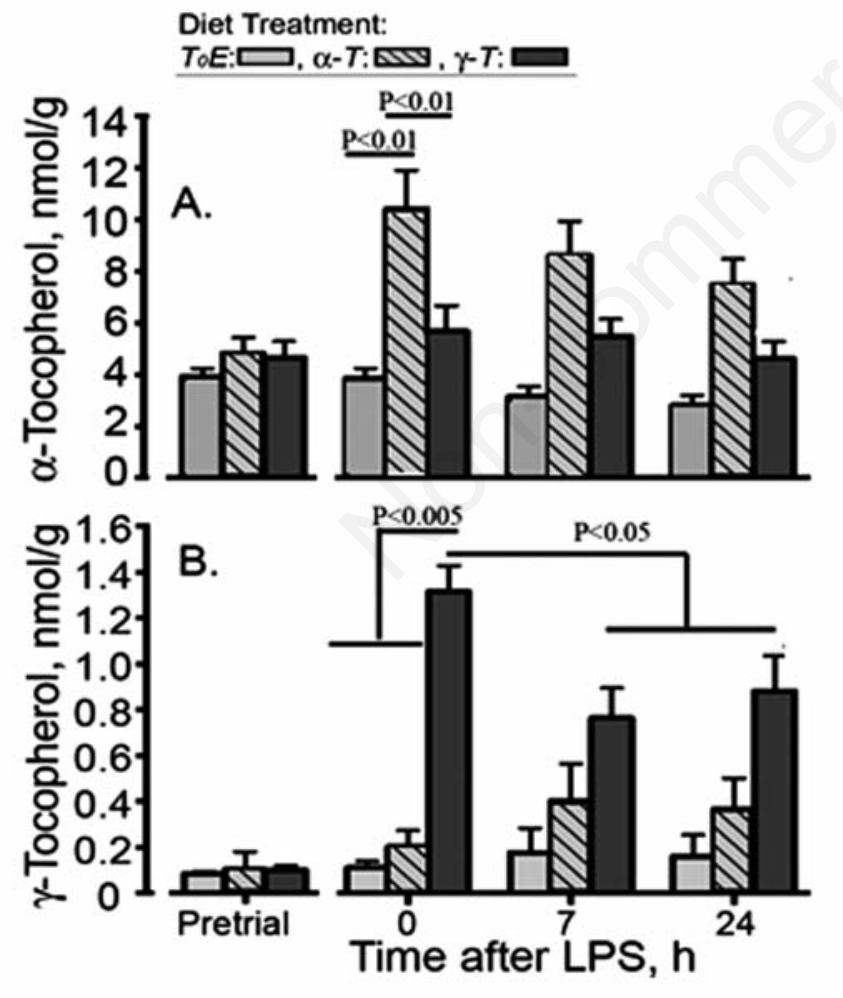

Figure 1. Plasma concentration of $\alpha$ - (A) and $\gamma$-tocopherol (B) in calves fed control diet (TOE) or diets supplemented with enriched isoform of $\alpha$-tocopherol $(\alpha-T$, Novatol TM 1490) or $\gamma$-tocopherol

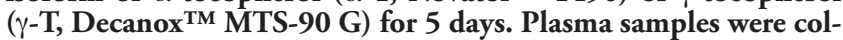
lected before the start of feeding tocopherols supplementation (Pretrial) and at 0,7 , and $24 \mathrm{~h}$ relative to LPS challenge. Data represent means \pm SEM.
Diet Treatment:

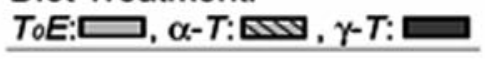
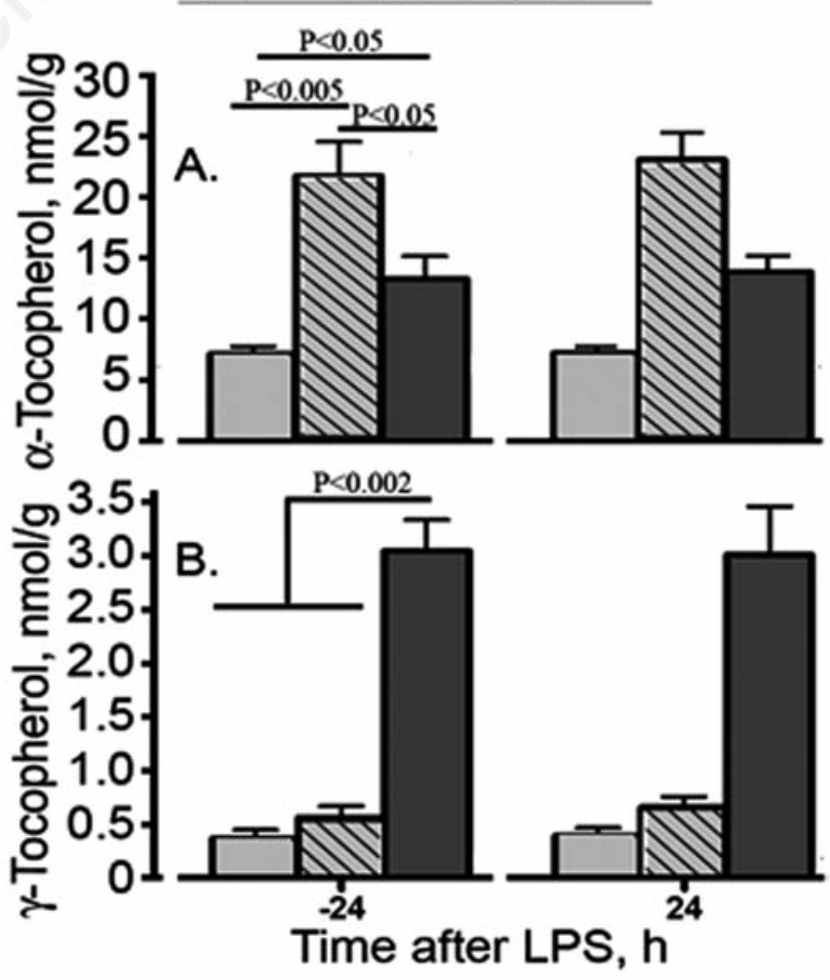

Figure 2. Liver concentration of $\alpha-(A)$ and $\gamma$-tocopherol (B) in calves fed control diet (TOE) or diets supplemented with enriched isoforms of $\alpha$-tocopherol ( $\alpha$-T, NovatolTM 1490) or $\gamma$-tocopherol $\left(\gamma\right.$-T, Decanox ${ }^{\text {TM }}$ MTS-90 G) for 5 days. Liver samples were collected $24 \mathrm{~h}$ before and $24 \mathrm{~h}$ after LPS challenge. Data represent means \pm SEM. 
gesting an effect of these tocopherol treatments to mitigate some of the stress associated with the preliminary sampling procedures. Following administration of LPS, plasma NOx concentrations increased in all animals irrespective of diet group. The increases in plasma NOx in response to LPS were significantly lower at the 7-h sampling in both the tocopherol supplementation groups compared to the control diet group $(\mathrm{P}<0.05)$ and not significantly different from the concentrations at time 0 . The increase in NOx averaged 21 $\mu \mathrm{mol} / \mathrm{L}$ compared to $12.5 \mu \mathrm{mol} / \mathrm{L}$ in either of the tocopherol diet groups $(\mathrm{P}<0.02)$. The response waned over the course of the next 17 h.

In the present study, the patterns of change in plasma SAA were reflective of the pattern of stress response events observed in the plasma NOx responses to cannulation, biopsy, and LPS challenge. Similar to plasma NOx, plasma SAA (Figure 5) concentrations increased significantly $(\sim 3$-fold, $\mathrm{P}<0.02) 24 \mathrm{~h}$ after cannulation and preliminary liver biopsy. Following LPS administration at time 0 , plasma SAA increased another 4 -fold $(\mathrm{P}<0.001)$ across treatments but irrespective of diet. At $24 \mathrm{~h}$ post LPS, concentrations of SAA were higher $(\mathrm{P}<0.04)$ than those measured in 7-h post LPS samples in TOE and $\alpha-T$. Plasma SAA concentrations from $\gamma$-T at $24 \mathrm{~h}$ post-LPS were not different from those measured in their respective 7-h samples and were significantly lower at that $24 \mathrm{~h}$ point than the circulating concentrations measured in samples from TOE and $\alpha-T$.

The impact of LPS challenge and modulating influence of tocopherol diet supplementation on the development of nitrosative stress in the liver is illustrated in Figure 6 where quantitative imunohistochemical determination of the nitrotyrosine content of liver cells is presented. In Figure 6, images under Panels A illustrate the actual immunohistochemical localization of $p N T$ (brown coloration) while images under Panel B highlight the identification of these specific immunolocalized pixels by the image analysis process employed (red pixel coloration), respectively. LPS challenge of control diet calves increased liver $p N T$ on average 5fold as estimated by nitrotyrosine pixel density per cell nucleus counted (Panel $\mathrm{C}, \mathrm{P}<0.002$ ). The liver nitration response in tissue from both tocopherol diet groups was significantly attenuated in comparison to that measured in the control diet group and the response did not differ statistically between $\alpha-T$ and $\gamma-T$.

The impact of proinflammatory challenge and dietary tocopherol treatment on the relative abundance of mitochondrial ATP-synthase was evaluated using antibodies against the $\alpha$ subunit of the F1F0 ATP-synthase region of bovine Complex V. All cells had some level of immunostaining (Figure 7, top panel) with the cells of sinusoids, cells lining central veins and cells associated with the portal triad having the highest basal staining intensity. In general, tocopherol treatment alone had no statistically significant effect on the level of F1F0 ATP-synthase prior to LPS administration. Challenge of animals with LPS resulted in an increase in mitochondrial F1F0 ATP-synthase in all calves (Figure 7, bottom panel) approaching an average across dietary treatment groups 2.5 -times the antigen intensity present under non-LPSstimulated states (Pre-v Post-LPS across all diets, $\mathrm{P}<0.01)$. Because the statistical model indicated a significant overall effect of tocopherol treatment (both tocopherol diets versus control, $\mathrm{P}<0.03$ ) to lower the magnitude of LPS-driven increase in F1F0 ATP-synthase, further separation of the individual treatment effects with contrast statements indicated that the attenuated effect was in large part carried by the numerically higher baseline prior to LPS in calves fed the diet high in $\gamma$ - and $\delta$-tocopherol. After LPS challenge, when the magni-
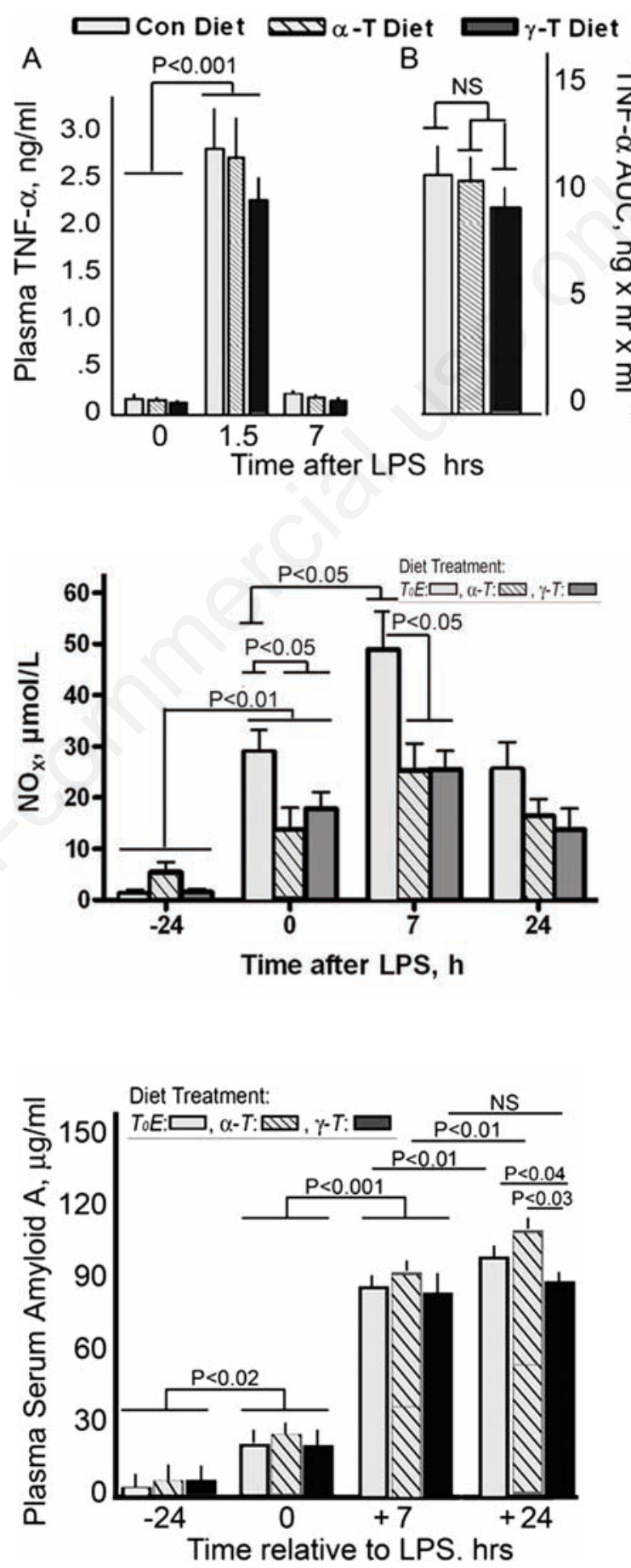

Figure 3. Plasma TNF- $\alpha$ concentration (A) and calculated TNF- $\alpha$ response to LPS challenge (area under the time $x$ concentration curve, $(B)$ in calves fed control diet (TOE) or diets supplemented with enriched isoforms of $\alpha$-tocopherol $\left(\alpha-T\right.$, Novatol $\left.^{\mathrm{TM}} 1490\right)$ or $\gamma-$ tocopherol $\left(\gamma-\mathrm{T}\right.$, Decanox ${ }^{\mathrm{TM}}$ MTS-90 G) for 5 days. Plasma samples were collected at $0,1.5$, and $7 \mathrm{~h}$ relative to LPS challenge. Data represent means \pm SEM.
Figure 4. Plasma nitrate+ nitrite $(\mathrm{NOx})$ concentration in calves fed control diet (T0E) or diets supplemented with enriched isoforms of $\alpha$-tocopherol $\left(\alpha-\mathrm{T}\right.$, Novatol $^{\mathrm{TM}}$ 1490) or $\gamma$-tocopherol $(\gamma-T$, Decanox $^{\text {TM }}$ MTS-90 G) for 5 days. Plasma samples were collected before liver biopsy procedure $(-24 \mathrm{~h})$ and at 0,7 , and $24 \mathrm{~h}$ relative to LPS challenge. Data represent means \pm SEM.

Figure 5. Plasma Serum Amyloid A (SAA) concentration in calves fed control diet (TOE) or diets supplemented with enriched isoforms of $\alpha$ tocopherol ( $\alpha-T$, Novatol $\mathrm{TM}$ $1490)$ or $\gamma$ - tocopherol $(\gamma-T$, Decanox $^{\text {TM }}$ MTS-90 G) for 5 days. Plasma samples were collected before liver biopsy procedure $(-24 \mathrm{~h})$ and at 0,7 , and $24 \mathrm{~h}$ relative to LPS challenge. Data represent means \pm SEM. 
tude of the increase was calculated as the difference (by calf within group) between its pixel intensity before versus after LPS, the incremental effects in the $\gamma$-T diet group (1.8 fold increase) was significantly lower $(\mathrm{P}<0.03$ v TOE; $\mathrm{P}<0.04 v \alpha-T)$ than those calculated for TOE and $\alpha$-T (3.9-fold and 3.3-fold for TOE and $\alpha-T$, respectively).

Mitochondria are capable of generating high levels of NO and superoxide anion in a confined space (inner compartment) in response to proinflammatory challenge and therefore potentially can generate high impact nitrations locally. To assess this potential for nitration, we evaluated the capacity for specific nitrations to occur in or in close proximity to affected mitochondria. To approximate this, we employed a novel assay, a proximity ligation assay, to detect the occurrence of nitration events in mitochondria by linking this protein to localized nitrated tyrosines and visualized as high intensity loci of varying size density. Figure 8 illustrates the generated signals specifying mitochondrial nitration as a function of the $\alpha$-subunit in mitochondrial F1F0 ATP-synthase. As can be observed, both the quantity of nitration events (red pixel dots) and the size density (pixel area) of the events was affected by both LPS administration and further modified by diet. In Panel A, tissue obtained from a herd animal sufficiently ill as to warrant veterinary euthanasia (positive control unrelated to present study animals) presented an image of intense nitration of the F1F0 ATP-synthase Complex V domain. In this rather extreme situation, the number of nitration events as well as the mean size of individual events are large compared to those that evolved from LPS chal- lenge. However, a comparatively mild challenge with LPS also presented a picture of increased nitration of mitochondrial proteins, as compared to the Pre-LPS challenge samples. The enlarged area of interest (AOI) is a representative image from a control diet animal following challenge with LPS emphasizing the range in size and density of the resolved colocalized signals. As seen in Panel G, supplementing calves with tocopherol-enriched diets decreased the mean number of nitration events, regardless of pixel area size, occurring in this mitochondrial target epitope relative to those quantified in tissues from the control diet group $(\mathrm{P}<0.05)$. We observed that the size and intensity of the resolved epitope nitration events in this protein appeared to vary between samples from the various treatment groups. Because the image analysis process

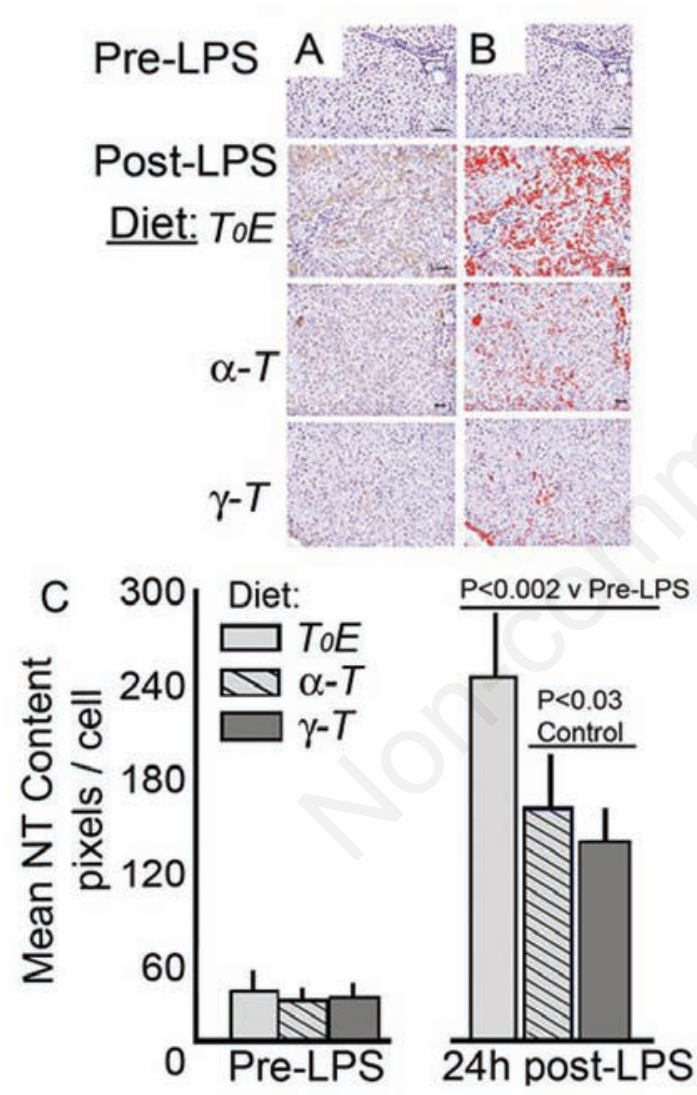

Figure 6. Immunohistochemical localization and image analysis quantification of the generation of protein tyrosine nitration in liver substructures as effected by LPS challenge and modified by diets without (T0E) or with supplemented isoforms of vitamin $\mathrm{E}$ ( $\alpha$-tocopherol: $\alpha$-T, Novatol ${ }^{\mathrm{TM}}$ 1490; $\gamma$-tocopherol, $\gamma$-T, Decanox $^{\mathrm{TM}}$ MTS-90 G). A) protein-associated nitrotyrosine (pNT, brown immunostaining) as detected by immunohistochemical localization with anti-nitrotyrosine serum (1:5000). B) Identification of the reacting antigen pixels as quantified by image analysis. Nuclei are stained blue. C) mean pNT content in liver as affected by LPS challenge and diet. Data represent means \pm SEM.

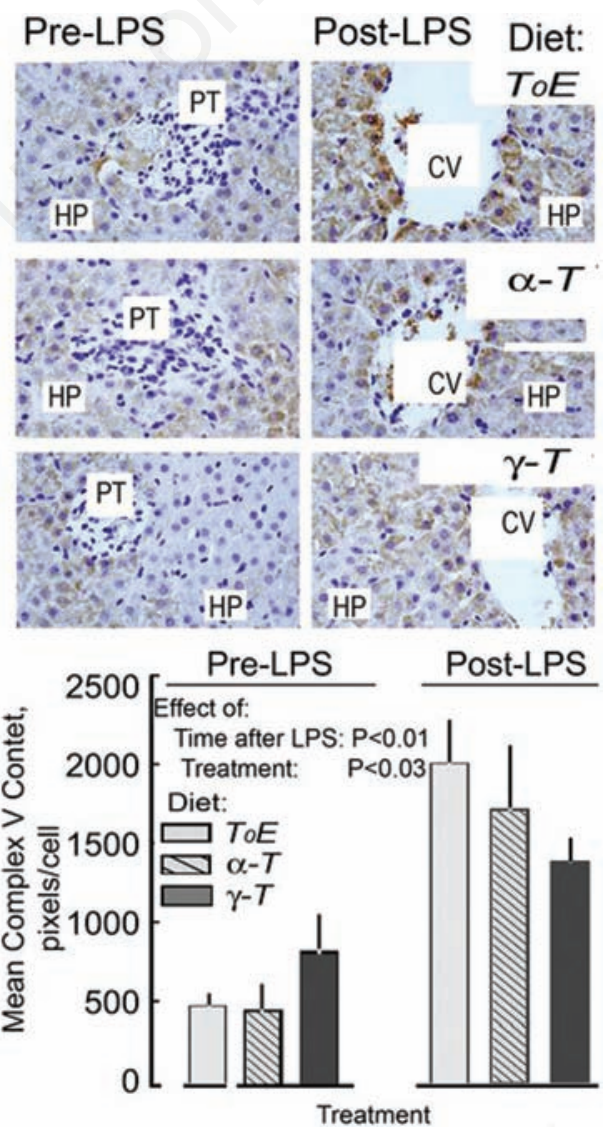

Figure 7. Immunolocalization of mitochondrial F1F0 ATP-synthase in liver (Complex V; Top panel, demarcated areas: PT, portal triad; HP, hepatocyte dominated; $\mathrm{CV}$, central vein) and quantification of the change in Complex $\mathrm{V}$ liver content (Bottom panel) as affected by diet supplementation with different tocopherol isoforms (TOE, control diet; $\alpha$-T, $\alpha$-tocopherol; $\gamma$-T, $\gamma$ tocopherol) and proinflammatory LPS challenge. Data in bottom panel represent means \pm SEM. 
was capable of capturing event data in terms of event size (pixel area), we decided to subject this data to mathematical frequency analysis to determine if the nature of the responses could be stratified by the number of events that occurred for a particular size range of events. Preliminary evaluation of the data indicated that the data were best fit to nonlinear models principally of either exponential or logarithmic trend $\left(\mathrm{R}^{2}>0.90\right)$. These curve forms then could be assessed using curve pealing to generate the two best-fit linear segments defining each animal's frequency curve and further generate the point at which the two lines intersected, a value we termed the break point. Indicative of the intensity of the nitration response, this break point signified the transition or inflec- tion point at which the data transformed from high frequency-low area events to lower frequency-higher area events (more intense). When these data are plotted (Panel H), it is clearly evident that tocopherol treatment decreases the number of high intensity nitration events in this target protein and it is further more apparent, as indicated by the mean break point value, that the supplementation of a diet with an oil rich in $\gamma$ - and $\delta$-tocopherol is highly effective in minimizing the generation of high intensity nitrations in mitochondria. Derived mean breakpoint values were $252 \pm 78$, $684 \pm 55,591 \pm 47$, and $312 \pm 86$ for control TOE, LPS- TOE, LPS- $\alpha-T$, and LPS- $\gamma-T$, respectively. Statistically, the mean break point value for high intensity responses within the control diet was 270\% greater in LPS-treated animals than non-LPS animals $(\mathrm{P}<0.01)$. Across LPStreated diet groups, the mean breakpoint value for $\alpha-T$ was $9 \%$ (NS) and for $\gamma-T 46 \%(\mathrm{P}<0.01)$ lower than that calculated for TOE. Regression curve fitting indicated that the logarithmic pattern was best-fit to the data from control TOE, $\left(R^{2}=0.946\right)$ while exponential curves were best fit to all data from LPS-challenged animals $\left(\mathrm{R}^{2}=0.955\right)$.

\section{Discussion}

The focus of the present work was directed towards assessing whether a short-term

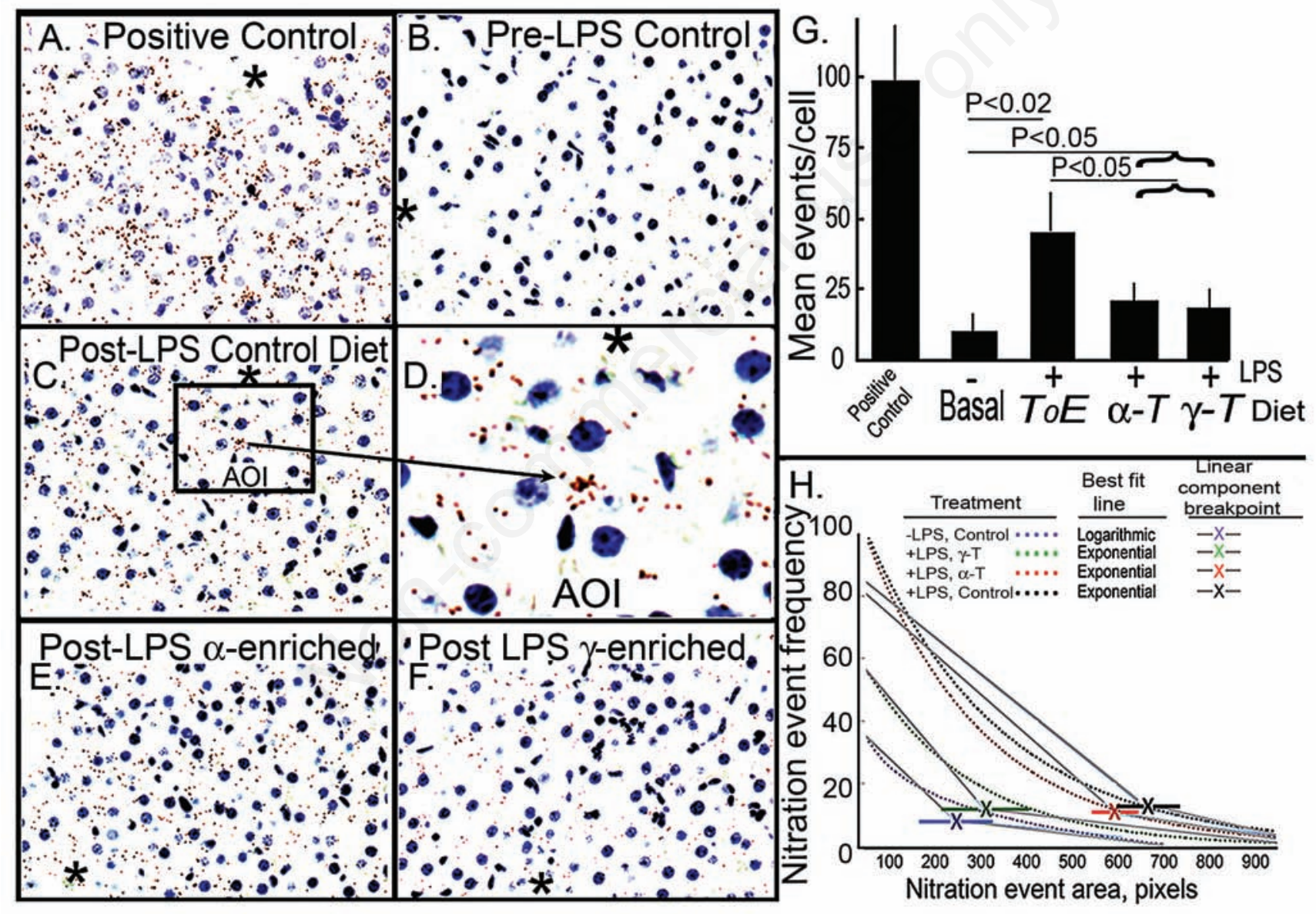

Figure 8. Proximity Ligation Assay (PLA) analysis of mitochondrial nitration. Red pixilated dots represent loci within cells where mitochondrial Complex V colocalized with nitrotyrosine antigenic signals. A): positive control illustrates a PLA image of tissue from an animal diagnosed with multiple organ septic shock. B) prior to LPS challenge, PLA data indicated a very low level of mitochondrial protein nitration. C) administration of LPS resulted in a significant increase in the number and size of nitration events; the enlarged area of interest (AOI) shows the greater intensity of the nitration events present. Tissues from animals fed either tocopherol-supplemented diet showed lower numbers of Complex V nitration events (E: $\alpha-T, \alpha$-tocopherol; F, $\gamma$-T, $\gamma$-tocopherol) than tissue from control animals (T0E diet). G) illustrates the simple mean number of Complex V nitration events per cell occurring in association with LPS challenge and dietary status. Data represent means \pm SEM. H) illustrates the results from curve peeling and fitting the frequency of nitration events to a particular pixel area of the recorded event. Dotted lines represent curves fitted to the mean number of nitration events for the given range in pixel areas. Solid lines represent the estimated linear fit components of each curve as derived from the curve peeling analysis. ${ }^{*}$ Indicate boundary for adjacent central vein regions demarcating regions of high NT immunostaining. 
dietary administration of either natural $\alpha$ tocopherol or mixed natural tocopherols high in $\gamma$ - and $\delta$ - isoforms would reduce the amount of protein tyrosine nitration generated during a low-level induction of endogenous proinflammatory mediators elicited with bacterial LPS. The calf was used as an animal model because of its greater sensitivity to LPS than rodent models and because many of the responses are similar to those observed in human low-level endotoxicosis,, 228 and in particular, because of the paucity of data in cattle describing tissue and plasma content of non- $\alpha$-isoforms in states of health or proinflammatory stress. The dose of LPS chosen here is consistent with the dose used many times previously in our laboratory, a dose that results in short-term febrile response and fever, minor depression in feed intake, increased generation of liver nitrated proteins and followed by recovery. We chose to investigate this phenomenon using tools associated with validated procedures for quantitative immunohistochemistry and proximity ligation assay for nitrated proteins because not all cells in a given tissue respond equally to given proinflammatory challenges and the differences could be characterized by cell type within tissue architecture. $.55,36$ Finally, we used this particular model and target tissue because of its capacity to a) address the need to mitigate the impact of disease stress on animals and humans, b) suggest cost-effective alternatives and adjuncts as a therapy largely without conventional drug residue issues, c) provides through feeding a practical and noninvasive route of administration, d) ensures distribution to the liver via the portal route from the digestive track and e) exploits the value of tyrosine nitration as a biomarker of nitrooxidative stress that has been well characterized in our laboratory in similar proinflammatory models of disease. $6,20,21,27-29$

There are two critical levels at which modulation of nitration can be effected: first, via altered generation of the $0 \mathrm{NOO}$-forming reactants $\mathrm{NO}$ and/or $\mathrm{O}_{2} \bullet$ and second, decreasing the probability of interaction of ONOO- with impact targets such as tyrosine residues. Data suggest that inhibition of NO and/or $\mathrm{O}_{2} \bullet$ is equivocal and problematic in regard to morbidity and mortality of clinical outcomes. ${ }^{37,38}$ Functional approaches to divert 0NOO- reactivity by delivering alternative targets to cells in vivo are just beginning to be tested. The benefit of this approach is that the reactive compound itself is targeted in cases of overproduction with fewer counterproductive impacts of collateral perturbation to signal transduction, vasoregulatory, or antimicrobial actions of $\mathrm{NO}$ and $\mathrm{O}_{2} \bullet$. With regard to general nitration patterns and the regional distribution of Complex V ATP-synthase, it was apparent that within different areas of the liver (pericentral venous, periportal triad, sinusoidal, etc.) there was more than a casual association between the levels of Complex V ATP-synthase. In fact, the density of cellular nitration mirrored the density of mitochondria suggesting that metabolically active liver regions are predisposed to a greater tyrosine nitration response during proinflammatory stress. Immunostaining patterns could be differentiated into areas of minimal to no immunostaining, areas of low to moderate staining progressing to areas of high-density immunostaining. This concept was further underscored where the signals generated to mark mitochondrial protein nitration as detected by proximity ligation assay were clustered and more evident in tissue regions containing the metabolically more active substructures.

The $\alpha$-isoform of tocopherols is considered the most biologically relevant, specified in terms of recommendation for daily allowances, ${ }^{23-25,39,40}$ and, for the most part, principally studied. Increasingly, however, it is recognized that the different tocopherol isoforms have biochemical impacts beyond antioxidant status, ${ }^{41,42}$ many of which even can be further traced to impacts on gene expression either directly, ${ }^{43}$ or via 0 NOO- modification of regulatory elements. ${ }^{37}$ As such, if ONO0-mediated alterations in biochemical processes are to be considered as contributing to a perturbation in a cellular function, then the tocopherol adsorption of this deleterious reactive oxynitrogen adduct can be considered productive towards reinstatement of homeostatic equilibrium. Though the $\gamma$-and $\delta$-isoforms are weaker antioxidants than $\alpha$-tocopherol, they are capable of reacting with ONOO- forming nitration products at the nonmethylated sites of the tocopherol ring structure with the potential to ameliorate 0NOOreactivity towards other molecular targets such as the phenolic group on tyrosine and these interactions are capable of taking place in vivo under situations of naturally-occurring proinflammatory metabolic disease. ${ }^{44-47}$ Data suggest that the reactions of the different tocopherol isoforms with nitrating compounds is relatively complex and made further intricate in regard to the simultaneous presence and interaction between the $\alpha$ - and $\gamma$ - isoforms. Steven et al. ${ }^{48}$ suggested that $\alpha$-tocopherol alone was sufficient to remove 0NO0-derived nitrating reactants from a biological matrix (liposomes) where their data indicated that the presence of $\alpha$-tocopherol attenuated the formation of both nitrated $\gamma$-tocopherol and the formation of nitrotyrosine. In addition, they noted that the presence of $\alpha$-tocopherol tended to inhibit or at least delay the nitration of $\gamma$ tocopherol by 0NOO- until available $\alpha$-tocopherol was depleted. Because this information was derived from artificial vesicles and in vitro incubations, we are conscious of the concern that the final conclusion regarding this effect occurring in vivo may necessitate modification according to how the tocopherols partition within different subcellular compartments and local domains of the cell and therefore interact with locally-generated nitrating reactants. Within the living biological matrix, this could be made more complex due to the distribution kinetics of the tocopherols in membrane structures and the physico-chemical relationships that dictate the relative accessibility of nitrating reagents to target tyrosines as well as tocopherols in hydrophobic and aqueous regions, lipid rafts and caveolae of membranes and biomolecules. ${ }^{49-51}$ It must be remembered, however, that many cellular receptor-mediated and stress sensing functions can be localized to these membrane subdomains and that it is in these localities that many aspects of the cellular response to stress are integrated, particularly in structures harboring NO synthase.6,52 Of course this is all dependent on the microenvironment in the cell and localized concentrations of the reactants. Collectively, these location-specific interactions may have had an effect in the present study in regard to the difference in overall effectiveness of the tocopherol formulations to differentially affect protein nitration potential in different subcellular compartments.

Though vitamin E has been used for decades in the animal production industry for everything from combating oxidative stress to increasing the color appeal to consumers and shelf-life of retail meat products, the specified use of concentrated natural oils as specific agents capable of impacting nitrosative stress in cattle has been investigated, for the most part, only by our laboratory. 6,21 The vast majority of domestic animal applications of tocopherol supplementation in the other mentioned applications were based on the use of a synthetic acetate or succinate form. Furthermore, in many citations in which the plasma or tissue levels of tocopherol were evaluated, it was only the $\alpha$-isoform measured or reported, to the exclusion of the $\gamma$-isoform and thus the present paper constitutes a first report of comparative tocopherol isoforms measured in plasma and liver, as affected by short-term feeding and further impacted by the inflammatory character of LPS challenge. Based on the product lot analysis of each tocopherol oil preparation, the estimated average daily intake/calf of supplemental $\alpha$-tocopherol was $1200 \mathrm{mg}$ and $260 \mathrm{mg}$ and that of $\gamma$-tocopherol was $<50 \mathrm{mg}$ and $2300 \mathrm{mg}$ in the $\alpha-T$ and $\gamma-T$ diets, respectively, levels significantly higher than those calculated to be present in the basal control diet.22 Our data clearly demonstrate that in the manner in which the tocopherol-containing oils were mixed and added to the diet, short-term feeding was effective in increasing both the plasma and tissue levels of $\alpha$ - or $\gamma$-tocopherols. It was interesting 
to note that in response to LPS challenge, over the $24 \mathrm{~h}$ during which the in vivo response was monitored, it was the plasma levels of $\alpha$-tocopherol that declined whereas liver and plasma levels of $\gamma$-tocopherol maintained a more-orless steady level. Though beyond our present scope of study, the data suggest that during active proinflammatory conditions organs like the liver strive to maintain their needed levels of tocopherols and pull these from the peripheral plasma as they are metabolized in responding tissues and cells. Plasma samples obtained prior to LPS challenge indicated that the short-term feeding of supplemental $\alpha$-tocopherol enriched oil did not significantly alter circulating concentrations of $\gamma$-tocopherol in calves, in contrast to the decrease in both $\gamma$ and $\delta$-tocopherols noted by Huang and Appel in studies where $\alpha$-tocopherol (acetate) was taken by human test subjects for two months as a supplement to their diet.53 0ur data suggest that the short duration of increased $\alpha$ tocopherol supplementation was sufficient to promote a beneficial effect towards thwarting acute onset proinflammatory nitration in general but without impact on $\gamma$-tocopherol concentrations in calves. Although the tissue ratio of $\alpha$ - to $\gamma$-isoforms changed as a function of respective diet, these ratios did not change between the before and post-LPS samples.

Administration of LPS was effective in inciting a proinflammatory response as assessed by several criteria: plasma concentrations of TNF$\alpha$ and NOx and liver content of nitrated proteins increased, as expected. What was not expected was that the TNF- $\alpha$ responses were not different between dietary treatment groups while the NOx response was differentially affected by supplement treatment with the tocopherol treatments presenting lower responses compared to animals fed the control diet. We consider this evidence consistent with previous suggestions from our lab that the proinflammatory cascade can be effectively modulated past the point of toll-like receptor 4 (TLR4)/TNF- $\alpha$ activation. ${ }^{6,52}$ In another experimental model we have observed a similar divergence in NOx response to LPS wherein, namely, the effects of estrogen and progesterone had modulatory impacts on NOx generation down-stream from proinflammatory cytokine responses. ${ }^{27}$ Similarly, the impact of the tocopherols supplied in the diets on the generalized and specific protein nitrations appear to be a function of which isoforms were predominant in the diet. These findings have bearing in regard to how one might interpret the data. Our laboratory's view is that the capacity to respond to a proinflammatory challenge is as a reflection of how well balanced cellular homeostasis is in light of impinging and sensed (in the endoplasmic and mitochondria) disturbances to a cell's well-being. This idea is exemplified by the overarching and conserved mechanisms that are effected within the unfolded protein response across such stresses as heat, bacterial toxin, heavy metals, anoxia, etc., and how large the insult is..$^{53-55}$

In consideration of the NOx and SAA data as biomarkers for the magnitude of stress impact, the overall effect of the tocopherols should be viewed as having had a beneficial effect on complex stress response where the first level of stress was associated with the pre-LPS cannulation and biopsy procedure the day before and then combined with the intended LPS challenge. In regard to the observed mitigating effects of the different tocopherol matricies on nitration when administered in advance of exposure to the proinflammatory challenge, two factors may have contributed to the beneficial outcome. First, the data are consistent with the concept that the increased cellular content of tocopherols improved the red-ox capacity of the cells resulting in a lower production of NOx and superoxide anion mediators, which further resulted in lower levels of ONOO- being generated. Second, when ONOOwas generated, the presence of the elevated tissue levels of $\gamma$-tocopherol in particular (any by inference $\delta$-tocopherol) were influential in decreasing further tyrosine nitrations which were injurious to cells. This heightened capacity for $\gamma$-tocopherol to downregulate injurious tyrosine nitrations was also noted previously. 46

An interesting feature of the present findings was that a) mitochondria appear to respond to the applied low-level proinflammatory challenge with increases in Complex $\mathrm{V}$ content. This could be interpreted as a compensatory mitochondrial action (mitogenesis) in response to the imposition of a metabolic stress proportional to the body's need to maintain, generate, and partition sufficient ATP for metabolic and survival purposes.6,56 The fact that the increases in F1F0-ATP-synthase $\alpha$ subunit as a measure of Complex V after LPS were lower in tocopherol-based diets, again, is consistent with the concept that the tocopherol matrix within the liver created an environment favorable to survival of the applied low-level proinflammatory state resulting in a lower stimulus (or need) to generate larger amounts of ATP. In contrast, however, the magnitude of effect of the two different tocopherol matricies to negate the intensity of mitochondrial protein nitration as estimated by the nitration signals generated by proximity ligation assay using antibodies to nitrotyrosine and F1F0ATP-synthase $\alpha$-subunit, suggest that the tocopherols decrease mitochondrial nitration and those oils rich in $\gamma$ - and $\delta$-tocopherol are more effective in mitigating this specific nitration. Using direct tetranitromethane-mediated reactions, Fujisawa et al. ${ }^{57}$ demonstrated that as few as two nitration events occurring in the F1F0-ATP-synthase $\beta$-subunit at tyrosine residues 345 and 368 were sufficient for ATP- synthase activity loss. 57 Associated with this, Haynes et al. 58 indicated that these nitrations were naturally present in mitochondria from aged rats with mitochondrial energy impairments. Wherein they argued that a significant impact on the nitratability of the selected tyrosine(s) was the degree to which the molecules were bound with ADP and $\mathrm{Mg}^{++}$where the bound residues had a lower nitration potential because of a localized charge hindrance that repelled 0NO0-. That data supports and is consistent with that of the present paper even though our data was derived from an antibody to the $\alpha$-subunit. In fact, as an exercise to complement the present experiment, when we applied Fletcher-Reeves molecular mechanics gradients (via Hyper-Protein ${ }^{\circledR} \quad 1.0$, HyperCube, Inc., Gainesville, FL USA) to peptides simulating the nitrated and nonnitrated tyrosine residues in the $\alpha$-subunit complementary to the tyrosine 345 of the $\beta$-subunit ADP binding pocket, ${ }^{59}$ the resulting difference in energy in the localized minima indicated that once nitrated, the charge state of any tyrosines in the ADP/Mg++ binding pocket was unfavorable to ADP binding; hence, the apparent termination of ATP formation. This proposed impact is supported by data indicating the complexity of dynamics in the reactions leading to the nitration of tyrosine by $0 \mathrm{NOO}$ in fluctuating oxidative and hypoxic states coupled with the reaction kinetics of ONOOwith tyrosine which are faster than the kinetics describing mitochondrial ATP-Pi exchange. 60,61

In regard to the physical distance characteristics of the proximity ligation assay used, antigen bridging will occur across regions separated by $40 \mathrm{~nm}$ or less. ${ }^{30}$ Therefore, the physical determinants (i.e., size and pixel density) of a mitochondrial protein nitration event will reflect not only intramolecular nitrations (a nitration in the same peptide) but also nitration events between interacting peptides of a protein complex or (as with the case with stressed mitochondria) as reflected in very large nitration events present in aggregated and clumped damaged proteins. ${ }^{52,55,58}$ For example, Complex V is a multimer of several peptide chains where the fundamental structural component of the rotor-stator mechanism that directs the attachment of phosphate to ADP to form ATP, can be localized to a pocket formed within the folds of the interacting $\alpha$ and $\beta$-subunits of the F1F0 ATP-synthase. For each heteromer of Complex $\mathrm{V}$ there are $3 \alpha$ chains and $3 \beta$-subunit chains containing 28 tyrosines between each paired $\alpha-\beta$ subunit complex ${ }^{58}$ totaling 84 . Using molecular modeling algorithms based on computational chemistry and data available for the $\alpha$ - and $\beta$-subunits of the membrane extrinsic region of bovine ATP Synthase [HTTP://www.ncbi. nlm.nih.gov/ Structure/mmdb/ mmdbsrv. 
cgi?uid=78135], we estimated that only a fraction of these tyrosine residues actually fit the amino acid sequence motif and hydrophobic and hydrophilic membrane location requirements necessary for nitration.6,16,19,52 However, where they do met criteria, substitutions of a nitrate moiety into the 3'- positions of the affected tyrosines causes significant destabilization of hydrogen bonding and generates stress on the molecule resulting in deformation around the associated $\alpha$-helix (data not presented). In fact two of the most critical residues needed for proper functioning of the catalytic and noncatalytic binding of ADP, phosphate, and $\mathrm{Mg}^{++}$reside in a specific fold of the $\alpha-\beta$ interaction and when nitration occurs in this epitope, the ATP generating capacity of the complex is lost. 57 Further information indicates that the functional complex in vivo exists minimally as a dimer and in most cases a multimeric supercomplex and it might be inferred that with cell-stress response mediated aggregation of these as well as the chance that other electron transport chain nitrations falling under the $40 \mathrm{~nm}$ umbrella of signal detection, 62 the potential for large high density mitochondrial protein nitrations increases geometrically and this is what is reflected in the proximity ligation assay data. Furthermore, our data suggest that the capacity for the tocopherols to mitigate much of this aberrant mitochondrial nitration and the effect of the $\gamma$-/ $/$-tocopherol supplementation in particular, reflects the inherent beneficial effect towards disrupting this stress pathway in mitochondria. Data are still sorely needed to better understand the subcellular partitioning of tocopherols into structures like the mitochondria. Collectively, the data herein suggest that feeding of tocopherol-enriched oils, especially oils enriched in $\gamma$ - and $\delta$ - isoforms, can impact acutely the generation of liver protein tyrosine nitration when fed in advance of a proinflammatory challenge and as such may be a useful adjunct in situations where prevention or intervention in aberrant protein nitration is considered a positive goal towards improved outcome from proinflammatory immune challenges.

\section{References}

1. Jaeschke H. Reactive oxygen and mechanisms of inflammatory liver injury: Present concepts. J Gastro Hepatol 2011;26:173-9.

2. YokoyamaY, Nimura Y, Nagino M, et al. Role of thromboxane in producing hepatic injury during hepatic stress. Arch Surg 2005;140:801-7.

3. Hardie G, Hawley S A. AMP-activated protein kinase: the energy charge hypothesis revisited. Bioessays 2001;23:1112-9.

4. Viollet B, Guigas B, Leclerc J, Hébrard S, et al. AMP-activated protein kinase in the regulation of hepatic energy metabolism: from physiology to therapeutic perspectives. Acta Physiol (Oxford) 2009;196:8198.

5. Yehuda-Shnaidman E, Kalderon B, Azazmeh N, Bar-Tana J. Gating of the mitochondrial permeability transition pore by thyroid hormone. FASEB J 2010;24:93104.

6. Elsasser TH, Caperna TJ, Li CJ, et al. Critical control points in the impact of the proinflammatory immune response on growth and metabolism. J Anim Sci 2008;86:E105-25.

7. Elsasser TH, Klasing K C, Filipov N, Thompson F. The metabolic consequences of stress: targets for stress and priorities of nutrient use. In: Moberg GP, Mench JA, eds. The biology of animal stress: basic principles and implications for animal welfare. New York: CABI Publishing; 2000. pp 77-112.

8. Kadenbach B. Intrinsic and extrinsic uncoupling of oxidative phosphorylation. Biochim Biophys Acta 2003;1604:77-94.

9. Berglund ED, Lee-Young RS, Lustig DG, et al. Hepatic energy state is regulated by glucagon receptor signaling in mice. J Clin Invest 2009;119:2412-22.

10. Ritz P, Dumas JF, Ducluzeau PH, Simard G. Hormonal regulation of mitochondrial energy production: nutrition in wasting disease. Curr Opin Clin Nutr Metab Care 2005;8:415-8.

11. Raha S, Robinson BH. Mitochondria, oxygen free radicals, and apoptosis. Am J Med Genet 2001;106:62-70.

12. Nijtmans LG, Ugalde C, Van den Heuvel LW, Smeitnik JA. Function and dysfunction in the oxidative phosphorylation system. In: Koehler CM, Bauer MF, eds. Mitochondrial function and biogenesis. New York; Springer Publications; 2004. pp 149-167.

13. Rich P. Chemiosmotic coupling: the cost of living. Nature 2003;421:583-7.

14. Castro L, Demicheli V, Tortora V, Radi R. Mitochondrial protein tyrosine nitration. Free Radic Res 2011;45:37-52.

15. Lacza C, Kozlov AV, Pankotai E, et al., Mitochondria produce reactive nitrogen species via an arginine-independent pathway. Free Radic Res 2006;40:368-78.

16. Greenacre SA, Ischiropoulos H. Tyrosine nitration: localisation, quantification, consequences for protein function and signal transduction. Free Radic Res 2001;34:54181.

17. Gow AJ, Farkouh CR, Munson DA, et al. Biological significance of nitric oxidemediated protein modifications. Am J
Physiol Lung Cell Mol Physiol 2004;287: L262-8.

18. Szabó C, Ischiropoulos H, Radi R. Peroxynitrite: biochemistry, pathophysiology and development of therapeutics. Nature Drug Disc 2007;6:662-8.

19. Ischiropoulos H. Protein tyrosine nitration-an update. Arch Biochim Piophys 2009;484:117-21.

20. Elsasser TH, Kahl S, MacLeod C, et al. Mechanisms underlying growth hormone effects in augmenting nitric oxide production and protein tyrosine nitration during endotoxin challenge. Endocrinology 2004;145:3413-23.

21. Elsasser TH, Kahl S, Li CJ, et al. Caveolae nitration of Janus kinase-2 at the 1007Y$1008 Y$ site: coordinating inflammatory response and metabolic hormone readjustment within the somatotropic axis. Endocrinology 2007;148:3803-13.

22. Committee on Animal Nutrition. Appendix tables. In: Nutrient Requirements of Beef Cattle. National Research Council, National Academy of Science Press. 1996; 7th Revised edition; Update 2000.

23. Galli F, Azzi A. Present trends in Vitamin E research. Biofactors 2010;36:33-42.

24. Traber MG. Vitamin E regulatory mechanisms. Ann Rev Nutr 2007;27:347-62.

25. Traber MG. Vitamin E bioavailability. In: Preedy VR, Watson RR, eds. The encyclopedia of vitamin E. CAB International; 2007. pp 221-230.

26. Podda M, Weber C, Traber MG, Packer L. Simultaneous determination of tissue tocopherols, tocotrienols, ubiquinols, and ubiquinones. J Lipid Res 1996;37:893-901.

27. Kahl S, Elsasser TH, Li CJ. Modeling the effects of estradiol and progesterone on the acute phase proinflammatory axis: variability in tumor necrosis factor- $\alpha$, nitric oxide, and xanthine oxidase responses to endotoxin challenge in steers. Domest Anim Endocrinol 2011;40: 213-21.

28. Kahl S, Elsasser TH, Blum JW. Nutritional regulation of plasma tumor necrosis factor- $\alpha$ and plasma and urinary nitrite/nitrate responses to endotoxin in cattle. Proc Soc Exp Biol Med 1997;215: 370-6.

29. Kahl S, Elsasser TH. Endotoxin challenge increases xanthine oxidase activity in cattle: effect of growth hormone and vitamin E treatment. Domest Anim Endocrinol 2004;26:315-28.

30. Gustafsdottir SM, Schallmeiner E, Fredriksson S, et al., Proximity ligation assays for sensitive and specific protein analyses. Anal Biochem 2005;345:2-9.

31. Abello N, Kerstjens HAM, Postma DS, Bischoff R. Protein tyrosine nitration: Selectivity, physicochemical and biological 
consequences, and proteomic methodsfor the detection of tyrosine-nitrated proteins. J Proteom Res 2009;8:3222-38.

32. Shipley RA, Clark RE. Tracer methods for in vivo kinetics: compartmental analysis of two-pool open systems. New York: Academic Press; 1972. pp 21-25.

33. Motulsky H, Cristopoulos A. Fitting models to biological data using linear and nonlinear regression: a practical guide to curve fitting. 2003. GraphPad Software Inc. San Diego, CA.

34. SAS Institute Inc. SAS/STAT® Software: Changes and Enhancements through Release 6.11. Cary, NC; SAS Institute Inc., 1996.

35. Teutsch HF. The modular architecture of the human liver. Hepatology 2005;42:31725.

36. Teutsch HF, Altemu, J, Gerlach-Arbeiter S, et al. Distribution of 3-hydroxybutyrate dehydrogenase in primary lobules of rat liver. J Histochem Cytochem 1992;40:2139.

37. Valco M, Leibfritz B, Moncol J, et al. Free radicals and antioxidants in normal physiological functions and human disease. Int J Biochem Cell Biol 2007;39:44-84.

38. Touyz RM. Reactive oxygen species, vascular oxidative stress, and redox signaling in hypertension: what is the clinical significance? Hypertension 2004;44:248-52.

39. Food and Nutrition Board, Institute of Medicine. Vitamin E. Dietary reference intakes for vitamin $\mathrm{C}$, vitamin $\mathrm{E}$, selenium, and carotenoids. Washington DC: National Academy Press; 2000. pp 186-283.

40. Mustacich DJ, Bruno RS, Traber MG. Vitamin E. Vit Horm 2007;76:1-21.

41. Traber MG. Regulation of xenobiotic metabolism, the only signaling function of alpha-tocopherol? Mol Nutr Food Res 2010;54:661-8.

42. Traber MG. Vitamin E regulatory mechanisms. Annu Rev Nutr 2007;27:347-62.
43. Li CJ, Li RW, Elsasser TH. Alpha-tocopherol modulates transcriptional activities that affect essential biological processes in bovine cells. Gene Regul Syst Bio 2010;4:109-24.

44. Christen S, Woodall AA, Shigenaga MK, et al. Gamma-tocopherol traps mutagenic electrophiles such as $\mathrm{NO}(\mathrm{X})$ and complements alpha-tocopherol: physiological implications. Proc Natl Acad Sci 1997;94: 3217-22.

45. Jiang Q, Lykkesfeldt J, Shigenaga MK, et al. $\gamma$-tocopherol supplementation inhibits protein nitration and ascorbate oxidation in rats with inflammation. Free Radic Biol Med 2002;33:1534-42.

46. Hoglen NC, Waller SC, Sipes, IG, Liebler DC. Reactions of peroxynitrite with $\gamma$-tocopherol. Chem Res Toxicol 1997;10:401-7.

47. Cooney RV, Harwood PJ, Franke AA, et al. Products of $\gamma$-tocopherol reaction with NO2 and their formation in rat insulinoma (RINm5F) cells. Free Radic Biol Med 1995;19:259-69.

48. Steven PA, Goss SPA, Hogg N, Kalyanaraman B. The effect of alpha-tocopherol on the nitration of gamma-tocopherol by peroxynitrite. Arch Biochem Biophys 1999;363:333-40.

49. Wang X, Quinn PJ. Vitamin E and its function in membranes. Prog Lipid Res 1999;38:309-36.

50. Bartesaghi S, Peluffo G, Zhang H, et al. Tyrosine nitration, dimerization and hydroxylation by peroxynitrite in membranes as studied by the hydrophobic probe N-t- BOC-tyrosine-tert-butyl ester. Meth Enzymol 2008;441:217-36.

51. Bartesaghi S, Ferrer-Suetal G, Peluffo G, et al. Protein tyrosine nitration in hydrophilic and hydrophobic environments. Amino Acids 2007;32:501-15.

52. Elsasser TH, Li CJ, Shaffer J, Collier RJ. Effects of environment on animal health: Mechanisms and regulatory inputs. In:
Collier RJ, Collier JL, eds. Environmental physiology of livestock. Oxford UK: WileyBlackwell Publications; 2012. pp 129-164.

53. Huang HY, Appel J. Supplementation of diets with $\alpha$-tocopherol reduces serum concentrations of $\gamma$ - and $\delta$-tocopherol in Humans. J Nutr 2003;133:3137-40.

54. Shen, X, Zhang K, Kaufman, RJ. The unfolded protein response - a stress signaling pathway of the endoplasmic reticulum. J Chem Neuroanat 2004;28:79-92.

55. Vögtle F N, Meisinger C. Sensing mitochondrial homeostasis: the protein important machinery takes control. Dev Cell 2012;23:234-6.

56. Clementi E, Nisoli E. Nitric oxide and mitochondrial biogenesis: a key to longterm regulation of cell metabolism. Comp Biochem Physiol 2005;142:102-10.

57. Fujisawa Y, Kato K, Giulivii C. Nitration of tyrosine residues 368 and 345 in the $\beta$ subunit elicits FoF1-ATPase activity loss. Biochem J 2009;423:219-31.

58. Haynes V, Traaseth NJ, Elfering S, et al. Nitration of specific tyrosines in FoF1 ATP synthase and activity loss in aging. Am J Physiol Endocrinol Metab 2010;298:E97887.

59. Abrahms JP, Leslie AGW, Lutter R, Walker JE. Structure at $2.8 \AA$ resolution of F1ATPase from bovine heart mitochondria. Nature 1994;370:621-8.

60. Aulak KS, Koeck T, Crabb JW, Stuehr DJ. Dynamics of protein nitration in cells and mitochondria. Am J Physiol Heart Circ Physiol 2004;286:H30-8.

61. Belogrudiv GI. Factor B is essential for ATP synthesis by mitochondria. Arch Biochem Biophys 2002;406:271-4.

62. Dudkina NV, Kou $\square$ il R, Peters K, et al. Structure and function of mitochondrial supercomplexes. Biochim Biophys Acta 2010;1797:664-70. 